\title{
Seasonal differences in the metabolisable energy concentration of kikuyu grass as predicted from in vitro gas production measurements
}

\author{
$M$ Herrero, RH Fawcett, JB Dent \\ Institute of Ecology and Resource Management, University of Edinburgh, West Mains Road, \\ Edinburgh EH9 3JG, Scotland
}

\begin{abstract}
Under most circumstances, environmental factors influence the seasonal nutritive value of forages. Therefore, monitoring these changes throughout the year is of primary importance in feeding programmes. Successful prediction of ruminant performance depends on the knowledge of the nutrient requirements of the species of interest, the nutritional value of feeds and their intake. Recently, the amount of gas produced and its kinetics when feed samples are incubated in vitro have been used successfully to describe their metabolisable energy (ME) concentration (Menke and Steingass 1988, Anim Res and Dev, 28, 7-55) ; and have been related to dry matter (DM) degradation, intake and growth rate of cattle (Blümmel and Ørskov, 1993, Anim Feed Sci and Tech, 40, 109-119) with accuracy. This study aims to describe the seasonal ME concentration of kikuyu grass as predicted from in vitro gas production.
\end{abstract}

Forty-eight pre-grazing samples from rotationally-grazed kikuyu grass (Pennisetum clandestinum) paddocks were collected from four dairy farms of the Poas highlands, Costa Rica during August-September, 1993 ; October-November, 1993 ; February-April, 1994 and May-July, 1994 (periods 1 to 4 respectively). The samples were incubated for in vitro gas production as described by Blümmel and Ørskov (1993) and measurements were taken at $3,6,12,24,36,48,72$ and 96 hours. The results were fitted to an exponential equation of the form $p=a+b\left(1-e^{(-c t)}\right)$
(McDonald, 1981, J Ag Sci, 96, 251-252). ME concentrations were estimated as described by Menke and Steingass (1988) for dry forages.

A two-way analysis of variance showed that significant seasonal differences existed between the predicted ME concentrations (see table). Samples from periods 1 and 2, which coincided with the rainy season had significantly higher $(P<0.001) M E$ than samples from season 3 (dry season). Samples collected during period 1 also had significantly higher ME concentrations than samples from period 4 which corresponded to the transition between the dry and wet seasons while samples from period 4 had higher ME concentrations $(P<0.05)$ than samples from period 3 . Farm differences or farm $X$ season interactions were not significant. The fitted asymptote values $(a+b)$ were not significantly different, but a stepwise regression analysis demonstrated that $57 \%$ of the variation in the seasonal ME concentrations could be explained by seasonal differences $(P<0.005)$ in the fractional rate of gas production per hour (parameter c (rate/h)). However when both variables were used together, $88 \%$ of the variation was explained. This suggests that as the prediction of ME is largely determined by the volume of gas produced at $24 \mathrm{~h}$. The shape of the gas production curve, particularly its initial slope, determines the magnitude of the ME concentration.

$\begin{array}{lcccc}\text { Period } & 1 & 2 & 3 & 4 \\ \text { ME (MJ/kg DM) } & 7.25 & 7.11 & 6.52 & 6.83 \\ \text { s.e. } & 0.107 & 0.147 & 0.146 & 0.125 \\ \text { c (rate/h) } & 0.0468 & 0.0432 & 0.0368 & 0.0414 \\ \text { s.e. } & 0.00266 & 0.00164 & 0.00125 & 0.00116 \\ \text { a }+ \text { b (ml gas) } & 45.01 & 45.99 & 45.76 & 44.02 \\ \text { s.e. } & 0.970 & 0.938 & 1.500 & 1.280\end{array}$

The authors acknowledge the discussions with Dr ER Ørskov. 